\title{
Endoscopic treatment of biliary obstruction in a patient with sump syndrome
}

Recurrent cholangitis occasionally occurs after choledochoduodenostomy, because of stagnant bile between the choledochoduodenostomy anastomosis and papilla a condition which is known as sump syndrome [1]. Several reports describe endoscopic sphincterotomy as useful for sump syndrome [2 -4]. Here we describe an 84year-old man showing sump syndrome with choledocholithiasis and biliary orifice obstruction, in whom endoscopic sphincterotomy was impossible.

After obtaining written informed consent, we performed stone extraction through the stoma and attempted biliary opening using two small-diameter endoscopes. One endoscope (GIF-XP260NS; Olympus, Tokyo, Japan) was advanced into the bile duct via the anastomosis after balloon dilation ( Fig. 1) as a cholangioscope. Direct visualization showed no orifice in the distal bile duct ( $\bullet$ Fig. 2 a, c). We inserted the other endoscope (FTS-530N; Fujinon, Saitama, Japan) into the duodenum as a duodenoscope. The cholangioscope was able to visualize the translucent phenomenon caused by the light from the duodenoscope through the papilla ( Fig.2a,d). The duodenoscope was used to observe the extramural compression phenomenon due to the cholangioscope ( Fig. 2 b,e). Using these two findings, we were able to correctly incise the terminal end of the bile duct (Endocut I, Effect 2, Duration 2, Interval 3; VIO300D; AMCO, Tokyo, Japan) using a needle knife (Zimmon Needle Knife Papillotomes; Cook, Tokyo, Japan) under direct vision using the cholangioscope, through observation with the duodenoscope and a fluoroscope. After making the incision ( $\bullet$ Fig. 3), we advanced the guide wire to the duodenum through the sheath of the needle knife. Using this guide wire ( Fig. 3), we successfully inserted an endoscopic biliary drainage tube through the artificial orifice.

Histopathological examination of the papilla revealed no malignant findings. No adverse events occurred during or after these procedures. After the treatment, the patient recovered from sump syndrome.
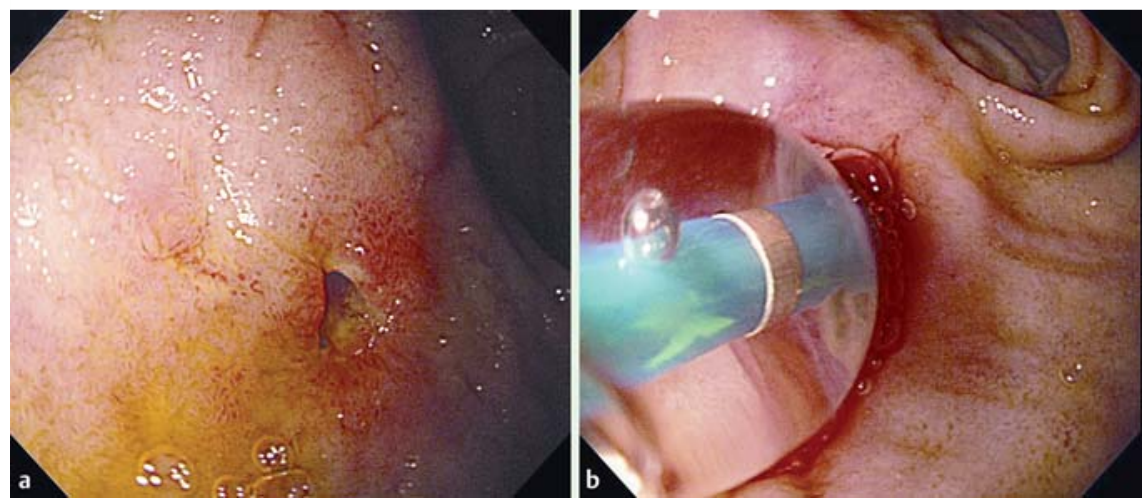

Fig. 1 a Endoscopic view of the choledochostomy stoma at the duodenal bulb. $\mathbf{b}$ Balloon dilation of the stoma was performed before stone extraction and insertion of a small-diameter endoscope.
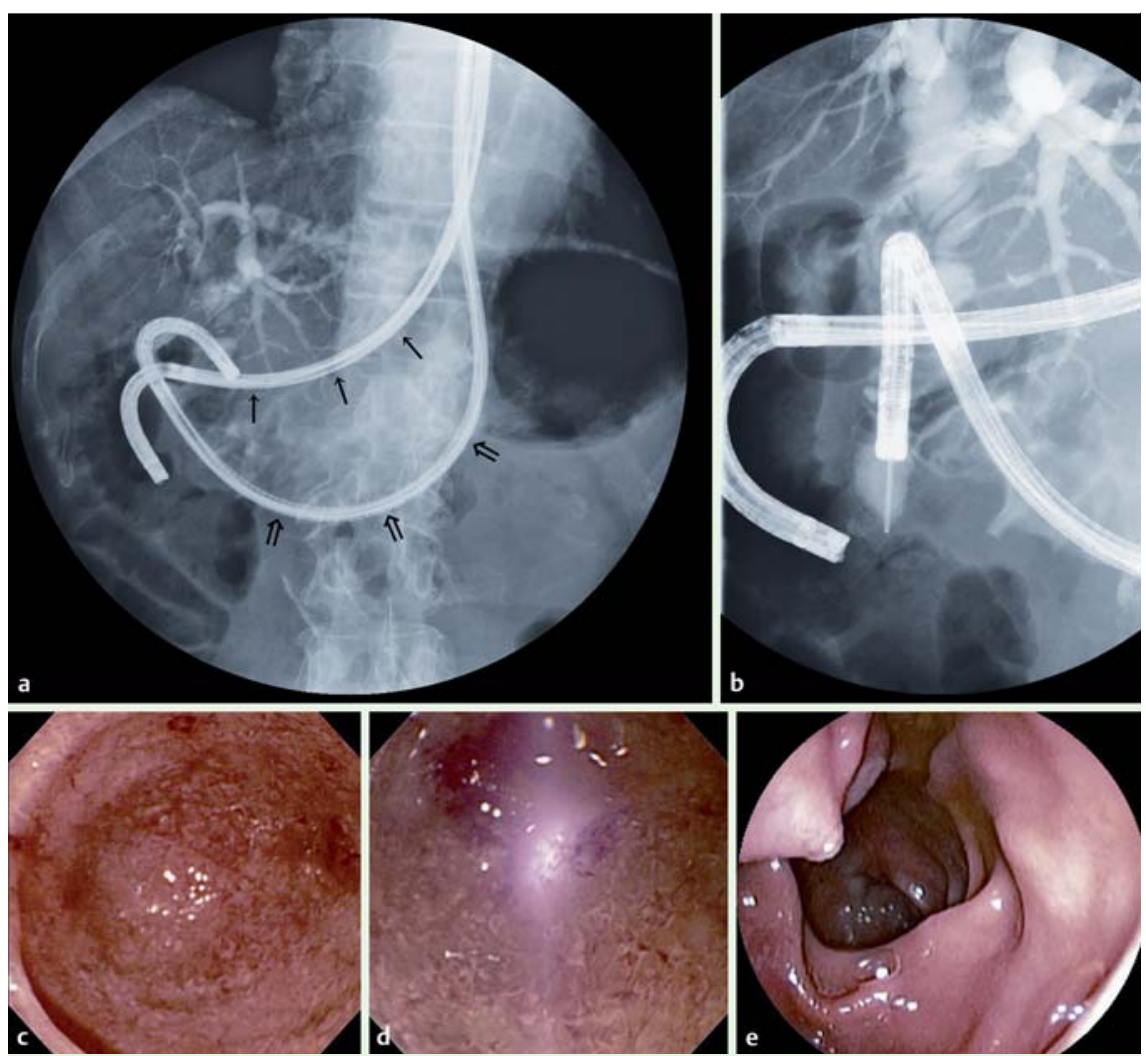

Fig. 2 a, b Fluoroscopy confirmed that the papilla was positioned in a "sandwich" fashion between the cholangioscope (thick arrows) and duodenoscope (thin arrows). c Direct visualization showed no orifice at the terminal end of the bile duct, although no tumorous lesion was noted. $\mathbf{d}$ The cholangioscope visualized the translucent phenomenon caused by the white light of the duodenoscope through the papilla. e The duodenoscope was used to observe the extramural compression phenomenon caused by the cholangioscope. 

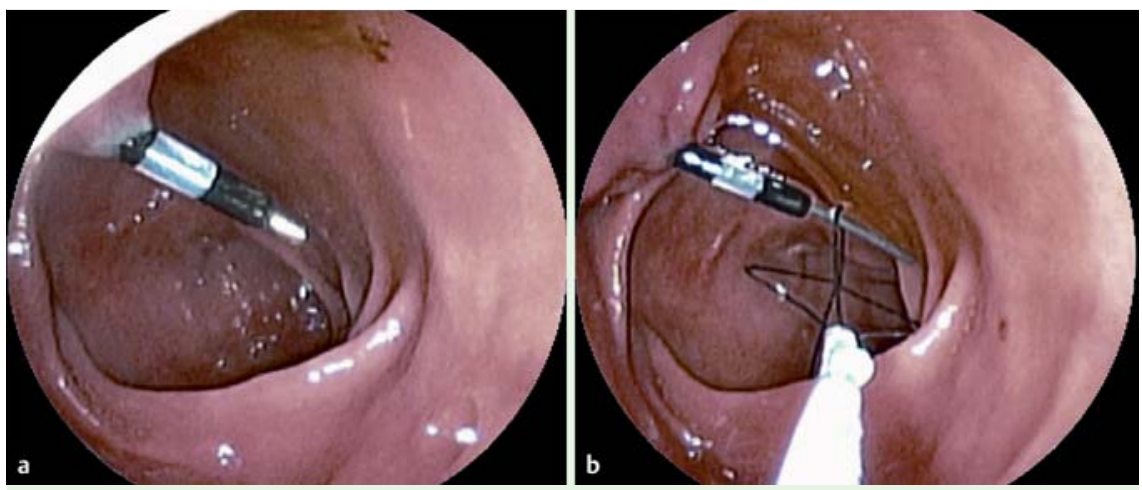

Fig. 3 Endoscopic view of: a the tip of the needle knife in the duodenum after incision of the biliary orifice; $\mathbf{b}$ using the guide-wire technique to insert an endoscopic biliary drainage tube through the artificial orifice.

This technique was useful for biliary orifice obstruction after choledochoduodenostomy. However, the findings are limited to this case report, therefore further evaluation should be performed in the future.

Endoscopy_UCTN_Code_TTT_1AR_2AG

\section{Competing interests: None}

\section{K. Fujita, Y. Harano, T. Morikawa, J. Andou, S. Myojo, S. Yoshida}

Gastroenterology, Tabata Gastrointestinal Hospital, Akashi, Hyogo, Japan

\section{References}

1 De Almeida AM, Cruz AG, Aldeia FJ. Side-toside choledochoduodenostomy in the management of choledocholithiasis and associated disease. Facts and fiction. Am J Surg 1984; 147: 253-259
2 Marbet UA, Stalder GA, Faust $H$ et al. Endoscopic sphincterotomy and surgical approaches in the treatment of the "sump syndrome". Gut 1987; 28: $142-145$

3 Caroli-Boso FX, Demarquay JF, Peten EP et al. Endoscopic treatment of sump syndrome after choledochoduodenostomy: retrospective analysis of 30 cases. Gastrointest Endosc 2000; 51: 02180-183

4 Christos M, Christos L, Andreas R et al. Sump syndrome: endoscopic treatment and late recurrence. Am J Gastroenterol 1999; 94: $972-975$

\section{Bibliography}

DOI http://dx.doi.org/

10.1055/s-0032-1309349

Endoscopy 2012; 44: E228-E229

(c) Georg Thieme Verlag KG

Stuttgart · New York

ISSN 0013-726X

\section{Corresponding author}

\section{K. Fujita, MD}

Gastroenterology

Tabata Gastrointestinal Hospital

111-1 Morita

Okubo-cho

Akashi

Hyogo 674-0061

Japan

Fax: +81-78-9361145

kfujita1017@gmail.com 